\title{
Type of Trellis Affects Radiation Absorption and Must Composition but not Yield of 'Petite Sirah' Grapes
}

\author{
T.H. Morsil, A.D. Matthias ${ }^{2}$, and J.L. Stroehlein ${ }^{3}$ \\ Department of Soil and Water Science, University of Arizona, Tucson, \\ AZ 85721
}

A dditional index words. radiation balance, PAR, wine, vineyard, V itis vinifera

\begin{abstract}
The effects of trellising on absorption of photosynthetically active radiation (PAR, 400- to 700-nm wavelength) by foliage and fruits, on fruit composition, and yield were studied in 1988 under semi-arid conditions using field-grown Vitis vinifera L. 'Petite Sirah' grapevines in a mature vineyard. A vertical inclination was obtained by attaching shoots to a vertically arranged three-wire trellis; $60^{\circ}$ shoot inclination from horizontal was obtained by attaching shoots to a "V-type" Tatura trellis; a standard two-wire trellis (control) was used in which shoots attached to the upper wire were permitted to orient downward to the vineyard floor. PAR absorption by foliage during mid-morning to mid-afternoon periods was highest in the standard trellis and lowest in the Tatura trellis. PAR available for absorption by fruits was lowest in the standard trellis and highest in the Tatura trellis. Analysis of fruit composition at harvest revealed that total dissolved solids ( ${ }^{\circ} \mathrm{Brix}$ ) was significantly higher for berries from the Tatura trellis than for the vertical trellis or the control. The Tatura trellis resulted in the highest alcohol content of wine. Per-vine yields did not differ significantly among the three trellis systems.
\end{abstract}

Trellis design is an important factor that influences the physiological and management aspects of grapevines (Smart, 1988; Smart et al., 1982, 1985; Van den Ende, 1984). Designs in which excessive shading of fruits by foliage occurs have generally reduced fruit quality and yield. A two-wire (Geneva Double Curtain) trellis design increased 'Concord' grape yields by as much as $90 \%$, relative to a singlewire (Kniffin) design, as a result of improved leaf and shoot exposure (Shaulis et al., 1966). The yield of 'Crouchen' grapes was increased up to $30 \%$ due to trellis widening from 0.3 to $1.4 \mathrm{~m}$ (May et al., 1976). Improved fruit exposure with four- and six-wire trellising systems increased 'Cabernet Sauvignon' yields by $45 \%$ and $48 \%$, respectively, relative to the yield from a standard two-wire trellis (Steinhauer and Bowers, 1979). Reynolds et al. (1986) found that the most exposed 'Seyval blanc' fruit had the highest $\mathrm{pH}$ levels, in addition to the highest ${ }^{\circ}$ Brix and tartrate content, and the lowest titratable acidity. Reynolds et al. (1986), however, reported no significant wine quality differences due to differences in fruit exposures. Recently, Patterson and Zoecklein (1990) showed that increased radiation penetration due to shoot positioning and removal of nonfruitful shoots resulted in superior fruit (i.e., reduced malate and potassium) relative to other treatments in 'Norton' grapes.

Received for publication 17 Dec. 1990. Accepted for publication 28 Aug. 1991. Journal article no. 7308 from the Arizona Agr. Expt. Sta, The cost of publishing this paper was defrayed in part by the payment of page charges. Under postal regulations, this paper therefore must be hereby marked advertisement solely to indicate this fact.

'Graduate Student.

${ }^{2}$ Associate Professor.

${ }^{3}$ Professor.
We present preliminary results from a field study in Arizona to determine the effects of three trellising systems on absorption of photosynthetically active radiation (PAR) by foliage and fruits, fruit composition, and yield of mature 'Petite Sirah' grapevines. This study was motivated by the need to determine optimal shoot positioning for the production of wine grapes in a hot, semi-arid climate, such as Tucson, because, to our knowledge, nothing has been published about the effect of shoot positioning on productivity of grapes grown in such a climate. Growth of wine grapes under high air temperatures and intense midday solar radiant energy fluxes requires efficient configuration of the vine canopy to achieve optimal radiation absorption by foliage, fruit shading, and fruit temperature conditions within the canopy. Excessive shading by foliage or excessive exposure to intense radiant energy may reduce fruit quality.

The experiment was conducted during the 1988 growing season at a 0.7-ha vineyard at the Univ. of Arizona Campus Agricultural Center, Tucson, using lo-year-old 'Petite Sirah' grapevines. This cultivar was chosen because it generally produces wines with adequate color and flavor in warm climates (Mielke et al., 1980). The vines were grown in Brazito sandy loam soil, which is classified as mixed thermic Typic Torrifluvents. The vines were basin-irrigated at $\approx 3$-week intervals. Spacing was $2.1 \mathrm{~m}$ between vines, with rows $3.3 \mathrm{~m}$ apart. Rows were oriented north-south. Before 1988 each vine had been trained to a standard two-wire trellis. All vines were spur-pruned in Jan. 1988 to 20 buds/ cordon with two cordons per plant. There were $\approx 20$ shoots/meter of row and $\approx 130$ leaves/shoot. Shoots were not pruned to a specific length during the growing season.

Three trellising designs were used to obtain three distinct shoot inclinations within the vineyard. The positioning of shoots on trellises resulted in canopies that were 1) positioned vertically (vertical canopy), 2) positioned in a "V" pattern with sides inclined $60^{\circ}$ from horizontal (inclined canopy), and 3 ) inclined toward the vineyard floor (standard canopy). The vertical canopy was obtained by attaching cordons and shoots to a vertically arranged three-wire trellis. The lower wire was used for cordon support, and the middle and upper wires were used to support shoots. Spacing between lower and middle wires was $0.46 \mathrm{~m}$, and spacing between middle and upper wires was $0.58 \mathrm{~m}$. This canopy was designed to provide increased PAR absorption and fruit shading near solar noon when incoming radiant energy fluxes were greatest. The inclined canopy was supported on a "V-type" Tatura trellis. This trellis consisted of five wires for support of cordons and shoots. A lower wire was used to support cordons. Four upper wires were attached to the ends of stacked 0.38and 0.76-m double crossarms for support of shoots. Spacing between crossarms was 0.58 $\mathrm{m}$. The inclined canopy was used to study the effect of decreased PAR absorption by foliage and decreased shading during midday periods. The standard canopy (control) was supported on a standard two-wire trellis with a 0.46-m spacing between the lower and upper wires. Shoots were attached to the upper wire and were permitted to orient downward toward the vineyard floor. This orientation resulted in a relatively dense foliage configuration that nearly enveloped the fruits and provided nearly total fruit shading from direct sunlight throughout the day. The standard trellis is commonly used in vineyards in the southwestern United States. Cordon height above ground for all three canopies was $\approx 0.9 \mathrm{~m}$. Establishment of vertical and inclined canopies occurred during Mar. 1988. A completely randomized design was used, consisting of the three treatments. Each canopy treatment was replicated eight times, with each replicate containing three vines. Data from the two outer (border) plants within a replicate were not collected; thus, data from only the middle vine were used in the study.

Components of the PAR budget of each type of canopy were measured on several clear days during the season using a $80-\mathrm{cm}$ long, Decagon Model SF-80 Sunfleck Ceptometer (Decagon, Pullman, Wash.). Measurements of the descending and ascending PAR $\left(\mu \mathrm{mol} \cdot \mathrm{m}^{-2} \cdot \mathrm{s}^{-1}\right)$ components of the budget were made at 0.5 -h to 2 -h intervals, typically from mid-morning to mid-afternoon, and were used to calculate the PAR absorbed by foliage (APAR) for each canopy design. Instantaneous APAR was calculated using Eq. 1 from Gallo and Daughtry (1986) given here as:

$$
\begin{aligned}
A P A R= & \left(P A R_{o}+R^{2} P_{s}\right)- \\
& \left(T P A R+\text { PPAR }_{c}\right)
\end{aligned}
$$

where PAR, is the PAR flux incident on the canopy, RPAR, is the PAR reflected from 
Table 1. Fractional amounts of PAR $_{\mathrm{o}}$ absorbed by foliage (APAR') and potentially absorbed by fruits (FPAR') of 'Petite Sirah' grapes as affected by trellis design., ${ }^{2, y}$

\begin{tabular}{|c|c|c|c|c|c|c|c|}
\hline \multirow[b]{3}{*}{ Date } & \multirow[b]{3}{*}{ Time } & \multicolumn{6}{|c|}{ Type of trellis } \\
\hline & & \multicolumn{2}{|c|}{ Standard } & \multicolumn{2}{|c|}{ Inclined } & \multicolumn{2}{|c|}{ Vertical } \\
\hline & & APAR' & FPAR $^{\prime}$ & APAR' & FPAR' $^{\prime}$ & APAR' & FPAR' $^{\prime}$ \\
\hline 9 June & $0830-1600 \mathrm{HR}$ & 0.86 & 0.07 & 0.66 & 0.18 & 0.72 & 0.18 \\
\hline 27 June & $0900-1430 \mathrm{HR}$ & 0.87 & 0.08 & 0.76 & 0.18 & 0.75 & 0.21 \\
\hline 29 June & $0900-1500 \mathrm{HR}$ & 0.85 & 0.08 & 0.77 & 0.27 & 0.73 & 0.30 \\
\hline $7 \mathrm{July}$ & $0900-1500$ HR & 0.85 & 0.11 & 0.67 & 0.38 & 0.74 & 0.33 \\
\hline 11 July & $0800-1600 \mathrm{HR}$ & 0.82 & 0.11 & 0.65 & 0.45 & 0.72 & 0.45 \\
\hline 12 July & $0800-1600 \mathrm{HR}$ & 0.85 & 0.07 & 0.74 & 0.32 & 0.77 & 0.29 \\
\hline \multicolumn{2}{|c|}{ Mean \pm SD } & $0.85 \pm 0.02$ & $0.09 \pm 0.02$ & $0.71 \pm 0.05$ & $0.30 \pm 0.11$ & $0.74 \pm 0.02$ & $0.29 \pm 0.10$ \\
\hline
\end{tabular}

${ }^{2}$ Daily means of 30 readings ( 10 per plant, three plants per trellising system).

${ }^{\prime} A P A R^{\prime}=A P A R$ : incoming PAR $\left(\right.$ PAR $\left._{0}\right)$ ratio and FPAR' = FPAR $:$ PAR $_{0}$ ratio.

the soil surface to the canopy, TPAR is the PAR transmitted through the canopy, and $\mathrm{RPAR}_{\mathrm{c}}$ is the total PAR reflected from the canopy and the soil. $\mathrm{PAR}_{\mathrm{o}}$ and $\mathrm{RPAR}_{\mathrm{c}}$ were measured at $\approx 1 \mathrm{~m}$ above the canopy using the leveled ceptometer facing either upward or downward, respectively. $\mathrm{RPAR}_{\mathrm{s}} \mathrm{w}$ as measured with the inverted ceptometer at $\approx 0.2 \mathrm{~m}$ above the soil surface. TPAR was measured by positioning the upright level ceptometer diagonally across the canopy at about the height of the basal fruits. Ten replicate measurements of each of the four PAR components on the right-hand side of Eq. [1] were made per plant for three plants within each canopy design. From these measurements, an average instantaneous APAR was determined from Eq. [1] for each canopy design. Daily (integrated) values of APAR (units of $\mathrm{MJ} \cdot \mathrm{m}^{-2}$ ) were then computed by numerical integration of the average instantaneous values of APAR determined throughout the day. In addition, the daily APAR values were computed as fractions of the daily $\mathrm{PAR}_{0} \mathrm{ac}-$ cording to: $\mathrm{APAR}^{\prime}=\mathrm{APAR} / \mathrm{PAR}_{\circ}$

PAR available for absorption by fruits (FPAR) at the base of each canopy was calculated as the sum of the PAR transmitted downward to the fruits through the foliage (TPAR) and the PAR reflected upward to the fruits from the soil surface (RPAR), i.e., FPAR $=$ TPAR + RPAR $_{s}$. Actual absorption of PAR by individual fruit clusters could not be measured directly by the ceptometer; thus, FPAR is only an indicator of the amount

Table 2. Characteristics of must in response to trellising of 'Petite Sirah' grapes.,

\begin{tabular}{lccc}
\hline \hline Trellis & ${ }^{\circ}$ Brix & $\mathrm{pH}$ & $\begin{array}{c}{ }^{\circ} \text { Brix : acid } \\
\text { ratio }\end{array}$ \\
\hline Standard & $13.3 \mathrm{a}$ & $3.50 \mathrm{a}$ & $14.5 \mathrm{a}$ \\
Inclined & $15.2 \mathrm{~b}$ & $3.46 \mathrm{ab}$ & $18.4 \mathrm{~b}$ \\
Vertical & $13.9 \mathrm{a}$ & $3.30 \mathrm{~b}$ & $16.0 \mathrm{ab}$ \\
\hline
\end{tabular}

${ }^{2}$ Means of eight vines per trellising system. of PAR available for absorption by the fruits. As done with APAR, FPAR was also converted to daily (integrated) values. Also, FPAR was expressed as a fraction of PAR on a daily basis according to: FPAR' = FPAR/PAR. Only FPAR' and APAR' values are presented.

The fruits were harvested 17 Aug. 1988, which was several days earlier than the normal harvest of 'Petite Sirah' at the end of August in Tucson (Mielke et al., 1980). Fruit was harvested early to avoid yield loss due to possible infestation by birds and insects. Fruit from each vine was weighed (kilograms per vine) and transported to the Univ. of Arizona Winery, Tucson. All grapes were crushed within $\approx 6 \mathrm{~h}$ after harvest. Must from each replicate vine was analyzed for total soluble solids (TSS; ${ }^{\circ}$ Brix), $\mathrm{pH}$, and titratable acidity (grams of acid/100 $\mathrm{ml}$ of juice) using procedures described by Amerine and Ough (1974). After chemical analysis of the juice from each of the eight replicates per treatment, the juices were combined to produce one batch of wine per treatment. The three finished wines were analyzed $\approx 6$ months after harvest for $\mathrm{pH}$, titratable acidity $(\mathrm{g} / 100$ $\mathrm{ml})$, volatile acidity $(\mathrm{g} / 100 \mathrm{ml})$, and alcohol (\%) by standard procedures (Amerine and Ough, 1974). Wine color was determined calorimetrically at 420 and $520 \mathrm{~nm}$ according to Amerine and Ough (1974). Statistical comparisons of treatment means (LSD at $P$ $=0.05$ ) for measured must attributes are reported. However, chemical characteristics for wine produced from each treatment were not tested statistically because juice from the replicates had been combined.

PAR absorption by foliage (APAR and APAR') during six midday periods was, on average, highest in the standard canopy treatment and lowest in the inclined canopy treatment (Table 1). PAR for those days was $\approx 30 \mathrm{MJ} \cdot \mathrm{m}^{-2}$. During midday, when heat and radiation levels were highest, $\approx 85 \%$ of the

Table 3. Characteristics of wine as affected by the trellising system for 'Petite Sirah' grapes. ${ }^{2, y}$

\begin{tabular}{|c|c|c|c|c|c|}
\hline \multirow[b]{2}{*}{ Trellis } & \multirow{2}{*}{$\begin{array}{c}\text { Alcohol } \\
(\%)\end{array}$} & \multicolumn{2}{|c|}{ Absorbance } & \multirow{2}{*}{$\begin{array}{c}\text { Titratable } \\
\text { acidity } \\
\left(\mathrm{g} \cdot 100 \mathrm{ml}^{-1}\right)\end{array}$} & \multirow[b]{2}{*}{$\mathrm{pH}$} \\
\hline & & $420 \mathrm{~nm}$ & $520 \mathrm{~nm}$ & & \\
\hline Standard & 6.5 & 0.12 & 0.16 & 0.620 & 3.49 \\
\hline Inclined & 9.4 & 0.20 & 0.31 & 0.527 & 3.41 \\
\hline Vertical & 6.9 & 0.15 & 0.23 & 0.426 & 3.60 \\
\hline
\end{tabular}

${ }^{2}$ Each wine produced from eight vines per trellising system.

${ }^{y}$ Wine analyzed $\approx 6$ months after harvest. incoming PAR (PAR) was absorbed by the foliage in the standard canopy, thus providing relatively uniform shading of fruits at the base of the canopy. This high percentage of midday $\mathrm{PAR}_{\mathrm{o}}$ absorption by foliage may increase photosynthesis and growth in the standard canopy relative to the others. In contrast to the standard canopy, the inclined canopy absorbed, on average, only $\approx 71 \%$ of $\mathrm{PAR}_{\circ}$, thus allowing for increased exposure of fruits, and potentially higher fruit temperatures. Similarly, the vertical canopy absorbed on average $\approx 74 \%$ of midday PAR $_{0}$.

Because of the open canopy architecture in the inclined and vertical canopies, $\approx 30 \%$ of $\mathrm{PAR}_{\circ}$ was potentially available for absorption by the fruits. This contrasted markedly with the average 9\% value of FPAR' for the standard canopy. In the standard canopy, there was much less radiation penetrating the canopy from the sky, as well as less radiation reflected from the vineyard floor into the vicinity of the fruits.

Mean $( \pm 1$ SD) fruit yields were $20.1 \pm$ $10.4,14.0 \pm 4.1$, and $16.9 \pm 5.2 \mathrm{~kg} / \mathrm{vine}$ for the standard, inclined, and vertical treatments, respectively. The large standard deviation in yields within each treatment (particularly for the standard canopy) resulted in nonsignificant mean yield differences (range 14.0 to $20.1 \mathrm{~kg} / \mathrm{vine}$ ). Nonsignificant yield differences are generally consistent with most previous studies of the effects of trellising on yield. Baldwin et al. (1979) found no differences in 'Sultana' yields due to six T-trellis treatments. They found, however, that three pruning levels did result in significant yield differences. Couvillon and Nakayama (1970) reported that yields of 'Concord' grapes grown on a two-wire crossarm (horizontal) trellis were higher than in a two-wire vertical trellis. Weaver et al. (1984) found that the highest ( $2 \mathrm{~m}$ tall $)$ trellis used resulted in the highest yield of 'Thompson Seedless' grapes, but the use of crossarms did not significantly increase yields, which is consistent with our results. Weaver and Kasimatis (1975), however, found that 'Thompson Seedless' vines trained on trellises with crossarms gave the highest yields. Buttrose (1970) reported that use of crossarm trellises did not increase yields of several cultivars because a lack of light penetration in the interior of the vines limited fruit bud differentiation and the light exposure of shoots, especially the basal portions. Shaulis 
and May (1971) suggested that the low amount of solar radiation penetrating the canopy on a standard T-trellis is a major factor limiting production of 'Thompson Seedless' grapes. They achieved higher yields by reducing shoot crowding through extension of canopy length and by reducing the number of nodes per unit canopy length.

The ${ }^{\circ}$ Brix for all three trellises (Table 2) was somewhat low compared to a typical ${ }^{\circ}$ Brix $\approx 21$ for 'Petite Sirah' in Tucson (Mielke et al., 1980), which may have been due in part to the early harvest. The ${ }^{\circ}$ Brix was significantly higher for the inclined canopy (by $14 \%$ ) than that for the standard or vertical (by 9\%) canopies. The ${ }^{\circ}$ Brix for grapes from the vertical and standard canopies was similar. The $\mathrm{pH}$ values were consistent with $\mathrm{pH} \approx 4$ for 'Petite Sirah' in Tucson (Mielke et al., 1980). The mean pH for the vertical canopy was significantly lower than that for the standard canopy, but there was no significant difference for berries from inclined and standard canopies. The titratable acidity levels were somewhat higher than expected $(\approx 0.48 \mathrm{~g} / 100 \mathrm{ml}$; Mielke et al., 1980 ), but they were not affected by the different positioning of shoots on the trellis systems (range 0.842-0.950 g-100 ml-1). However, the ${ }^{\circ}$ Brix : acid ratio was significantly higher for the inclined than for the standard canopy.

The relatively low ${ }^{\circ}$ Brix for berries in each treatment resulted in an alcohol content below the expected level of $\approx 10 \%$ (Mielke et al., 1980) (Table 3). The wine from berries of the inclined canopy had a higher alcohol content than that from either the standard or the vertical canopies. The color of wine from the inclined and vertical canopy treatments was excellent and consistent with the results of Mielke et al. (1980) (absorbances of $\approx 0.19$ and 0.22 at 420 and $520 \mathrm{~nm}$, respectively). However, the wine from the standard canopy treatment had $37 \%$ and $27 \%$ lower absorbances at 420 and $520 \mathrm{~nm}$, respectively, than Mielke et al. (1980) reported. Titratable acidity of wine from the standard canopy was $\approx 25 \%$ above the typical level of $\approx 0.5 \mathrm{~g} \cdot 100$ $\mathrm{ml}^{-1}$. The $\mathrm{pH}$ values of wine from the three canopies were $\approx 10 \%$ higher than the results of Mielke et al. (1980). The wine chemistry results were consistent with those for the must (Table 2).

The values for ${ }^{\circ}$ Brix and titratable acidity are consistent with results of Kasimatis et al. (1976), whose four-wire trellis produced fruit with a higher ${ }^{\circ}$ Brix than did the single-wire trellis. Steinhauer and Bowers (1979), how- ever, found ${ }^{\circ}$ Brix unaffected by trellis treatment (two-, four-, and six-wire) or yield differences of 'Cabernet Sauvignon'. Also, the concentration of sugars and acids and the mean berry weight in 'Crouchen' were unaffected by trellis width (0.3 to $1.4 \mathrm{~m})$ and pruning treatments (May et al., 1976). Hedberg and Raison (1982) concluded that the tendency for 'Shiraz' vines with close rows to have lower ${ }^{\circ}$ Brix than wider-spaced and trellised vines is related to the shaded horizontal canopies that developed. Kliewer and Lider (1968) found that increased fruit cluster exposure to sunlight reduced total acidity and malate concentration, and $\mathrm{pH}$. The higher $\mathrm{pH}$ in the musts produced from the fruits of the standard two-wire trellis in our study is consistent with data obtained by Smart et al. (1982, 1985). May et al. (1976) found that widening the trellis did not significantly affect ${ }^{\circ} \mathrm{Brix}$ of the juice, $\mathrm{pH}$, and acidity of the wine. However, they found that acidity tended to decrease and sugar concentration tended to increase with increasing yield.

The PAR absorbed by foliage and available for absorption by fruit differed among the three trellising treatments. Highest PAR absorbance by the standard canopy did not, however, significantly affect yield. Similarly, the inclined canopy treatment increased the sugar content of fruits at harvest and appeared to improve the wine quality characteristics relative to the other two trellises. Differences in must characteristics can be achieved through modification of the fruit microclimate by canopy management, but long-term studies are needed to determine the magnitudes of these differences and their effect on the quality of the wine.

\section{Literature Cited}

Amerine, M.A. and C.S. Ough. 1974. Wine and must analysis. Wiley, New York.

Baldwin, J.G., G.E. Bleasdale, R.S., Cadman, and I.L. Keens. 1979. Comparison of trellises and pruning levels for Sultana vines in the Murray Valley. Austral. J. Expt. Agr. Animal Husbandry 19:634-640.

Buttrose, M.S. 1970. Fruitfulness in grapevines: The response of different cultivars to light, temperature and daylength. Vitis 9:121-125.

Couvillon, G.A. and T.O.M. Nakayama. 1970. The effect of the modified Munson training system on uneven ripening, soluble solids, and yield of 'Concord' grapes. J. Amer. Sot. Hort. Sci. 95:158-162.

Ende, Van den B. 1984. The Tatura trellis-A system of growing grapevines for early and high production. Amer. J. Enol. Viticult. 35:82-87. Gallo, K.P. and C.S.T. Daughtry. 1986. Techniques for measuring intercepted and absorbed photosynthetically active radiation in corn canopies. Agron. J. 78:752-756.

Hedberg. P.R. and J. Raison. 1982. The effect of vine spacing and trellising on yield and fruit quality of Shiraz grapevines. Amer. J. Enol. Viticult. 33:20-30.

Kasimatis, A.N., L.A. Lider, and W.M. Kliewer. 1976. Increasing growth and yield of Thompson Seedless vines by trellising. Calif. Agr. 30(5):1415.

Kliewer, W.M. and L.A. Lider. 1968. Influence of cluster exposure to the sun on the composition of Thompson Seedless fruit. Amer. J. Enol. Viticult. 19:174-181.

May, P., P.R. Clingeleffer, and P.B. Scholfield. 1976. The response of the grape cultivar Crouchen (Australia syn. Clare Riesling) to various trellis and pruning treatments. Austral. J. Agr. Res. 27:845-856

Mielke, E.A., G.R. Dutt, S.K. Hughes, W.H. Wolfe, G.J. Loeffler, R. Gomez, M.D. Bryant, J. Watson, and S.H. Schick. 1980. Grape and wine production in the four comers region: Univ. of Arizona, Agr. Expt. Sta., Tech. Bul. 239.

Patterson, W.K. and B.W. Zoecklein. 1990. Vegetative and berry chemistry response to canopy manipulation and ethephon in 'Norton' grapes. HortScience 25:905-908.

Reynolds, A.G., R.M. Pool, and L.R. Mattick. 1986. Influence of cluster exposure on fruit composition and wine quality of Seyval blanc grapes. Vitis 25:85-95.

Shaulis, N.J., H. Amberg, and D. Crowe. 1966. Response of Concord grapes to light, exposure and Geneva Double Curtain training. Proc. Amer. Sot. Hort. Sci. 89:268-280.

Shaulis, N.J. and P. May. 1971. Response of 'Sultana' vines to training on a divided canopy and to shoot crowding. Amer. J. Enol. Viticult. 22:215-222.

Smart, R.E. 1988. Shoot spacing and canopy light microclimate. Amer. J. Enol. Viticult. 39:325333

Smart, R.E., J.B. Robinson, G.R. Due, and C.J. Brien. 1985. Canopy microclimate modification for the cultivar Shiraz. II. Effects on must and wine composition. Vitis 24:119-128.

Smart, R.E., N.J. Shaulis, and E.R. Lemon. 1982. The effect of Concord vineyard microclimate on yield. II. The interrelations between microclimate and yield expression. Amer. J. Enol. Viticult. 33:109-116.

Steinhauer, R.E. and K.W. Bowers. 1979. Influence of trellis on yield and quality of Cabernet Sauvignon in Napa Valley. Amer. J. Enol. Viticult. 30:236-240.

Weaver, R.J. and A.N. Kasimatis. 1975. Effect of trellis height with and without crossarms on yield of Thompson Seedless grapes. J. Amer. Sot. Hart. Sci. 100:252-253.

Weaver, R.J., A.N. Kasimatis, J.O. Johnson, and N. Vilas. 1984. Effect of trellis height and crossarm width and angle on yield of Thompson Seedless grapes. Amer. J. Enol. Viticult. 35:9496. 